\title{
Correspondence
}

Journal of Medical Genetics 1986, 23, 188-191

\section{A study of retinitis pigmentosa in the City of Birmingham}

SIR,

We think it useful to add some follow up information to the above papers. ${ }^{1}$

Firstly, since the paper was submitted for publication in May 1984, we have not ascertained, either in the Retina Clinic of the Birmingham and Midland Eye Hospital, or in the Diabetic Clinic of the General Hospital, any further patients with retinitis pigmentosa who had symptoms on prevalence day. We therefore believe that our observations on the prevalence of retinitis pigmentosa ${ }^{1}$ are correct.

Secondly, we had attempted by examination of relatives to identify the type of retinitis pigmentosa occurring in 12 severely affected male index patients who had no symptomatic relative. Three of the 12 patients were recognised as having $X$ linked retinitis pigmentosa, one did not have $\mathrm{X}$ linked disease because his adult daughter was not a carrier, and eight could not be classified. Two of those eight men are now discovered to have $\mathrm{X}$ linked disease, as the young sons of a sister and a daughter respectively have become affected. Their mothers were not available for earlier examination. This means that the likelihood of an isolated male with severe retinitis pigmentosa having the $\mathrm{X}$ linked form is about 1 in 2. In our whole series (regardless of severity or family history) we now have 21 male index patients out of 74 with $\mathrm{X}$ linked disease, an occurrence of about 1 in 3.5 .

We have not yet encountered a male with $X$ linked retinitis pigmentosa whose mother had healthy retinae.

\section{Sarah Bundey and S James CRews Clinical Genetics Unit, Birmingham Maternity Hospital, and Birmingham and Midland Eye Hospital, Edgbaston, Birmingham B15 2TG.}

\footnotetext{
Reference

1 Bundey S, Crews SJ. A study of retinitis pigmentosa in the City of Birmingham. I Prevalence. II Clinical and genetic heterogeneity. J Med Genet 1984;21:417-28.
}

\section{Cornelia de Lange syndrome}

SIR,

I was interested to read the article by Kumar et al ${ }^{1}$ describing Cornelia de Lange syndrome in several members of the same family. My first impressions were that neither the facial features nor the hand abnormalities were really consistent with the diagnosis of de Lange syndrome. A diagnosis of Ruvalcaba syndrome ${ }^{2}$ seems at least a possibility. The facial features and hand abnormalities are very similar, and the inheritance with variable dominant transmission would also fit. A relatively loose search of a computerised data base ${ }^{3}$ of 1250 syndromes from published reports showed 21 syndromes with the combination of eyebrow and hand anomalies. Of these, only the Ruvalcaba syndrome fitted the cases of Kumar et al (if one excludes the possibility of de Lange syndrome).

Radiographs of the hands, feet, and spine in the cases of Kumar et al would be most instructive, as these would most likely provide extra support for the diagnosis of Ruvalcaba syndrome.

\section{The Kennedy-Galton Centre for Clinical Genetics, Harperbury Hospital, Harper Lane, Shenley, \\ Radlett, Herts WD7 $9 H Q$.}

\section{References}

${ }^{1}$ Kumar D, Blank CE, Griffiths BL. Cornelia de Lange syndrome in several members of the same family. $J$ Med Genet 1985;22:296-300.

${ }^{2}$ Ruvalcaba RHA, Reichert A, Smith DW. A new familial syndrome with osseous dysplasia and mental deficiency. $J$ Pediatr 1971;79:450-5.

3 Winter RM, Baraitser M, Douglas JM. A computerised data base for the diagnosis of rare dysmorphic syndromes. $J$ Med Genet 1984;21:121-3.

A pedigree study of perinatally lethal renal disease SIR,

Bankier et al (J Med Genet 1985;22:104-11) are to be congratulated on their thorough study of perinatally lethal renal disease. Of interest, with regard to the group classified by them as multiple defects, is our case. 
On 24.6.83, a 24 year old primipara in good health gave birth to a stillborn male fetus with multiple defects and the appearance of Potter's syndrome. Birth weight was $1775 \mathrm{~g}$ after a gestation of 36 weeks and a pregnancy complicated by polyhydramnios. At necropsy there was bilateral renal agenesis, absent ureters (bladder present), absent penis, imperforate anus, and a persistent truncus arteriosus. Owing to collapse of the skull, the cranium was not opened.

Following this, in November 1983, a four month macerated fetus required induction and delivery by $\mathrm{D}$ and $\mathrm{C}$, and ten months later she delivered a missed abortion.

Because of this early fetal loss in conjunction with the previous malformed infant a karyotype was done on her and her husband. She showed a female karyotype with two apparently balanced translocations: $46, \mathrm{XX}, \mathrm{t}(2 ; 13)(\mathrm{p} 21 ; \mathrm{q} 32)$ and $\mathrm{t}(5 ; 14)(\mathrm{q} 33 ; \mathrm{q} 32)$. This indicated a very 'high' risk of reproductive failure. Her mother had one of the balanced translocations and had had two spontaneous abortions, as well as two sons and this daughter. One son, whose wife is currently 13 weeks pregnant, was found to have a normal karyotype. The family history showed a maternal female cousin who had Down's syndrome with no karyotype available.

This case demonstrates that recurrence risks for perinatally lethal renal disease in association with multiple defects may not only relate to autosomal recessive genes, as suggested by Bankier $e t$ al, but may also show a chromosomal cause. It is therefore important to karyotype such infants because of the consequent high risk implications to other family members.

\section{Athel Hockey, June Crowhurst, AND IAN WALPOLE* \\ Genetic Counselling Clinic,} King Edward Memorial Hospital for Women; and ${ }^{*}$ University Department of Child Health, Princess Margaret Hospital for Children, Subiaco, Western Australia 6008.

\section{Mosaic trisomy 9}

SIR,

In $1982^{1}$ we published a case of mosaic trisomy 9 and delineated the clinical phenotype of this unusual trisomy. As there have been fewer than 30 patients reported so far, and since many of them died during the first year of life, there is little information about their development. For this reason we wish to report the development of our patient, who is now $4 \frac{1}{2}$ years old.
At 6 months the patient, a girl, had a urinary infection. Pyelography showed mild left pelvic dilatation. Cardiological studies were normal. At 20 months she had a convulsive episode; as she has been taking luminal ever since, the episode did not recur. When she was 2 years she was operated on for cataracts in the right eye. She has dorsal kyphoscoliosis and pes valgus.

With regard to developmental milestones, she stood up at 22 months and walked at 4 years. At present she does not speak. She is severely mentally retarded and has severe microcephaly $(45 \mathrm{~cm}=50$ th centile for 1 year). Her mother became pregnant again last year and prenatal diagnosis showed a $46, \mathrm{XX}$ karyotype.

J M SÁNCHEZ

Fundación de Genética Humana, Salta 661, 1074 Buenos Aires, Argentina.

\section{Reference \\ 1 Sánchez JM, Fijtman N, Migliorini AM. Report of a new case and clinical delineation of mosaic trisomy 9 syndrome. $J$ Med Genet 1982;19:384-7. \\ Spondyloepiphyseal dysplasia tarda with progressive arthropathy: a rare disorder frequently diagnosed among Arabs}

Sir,

Spondyloepiphyseal dysplasia tarda with progressive arthropathy (SEDT-PA) is a newly delineated clinical disorder, ${ }^{12}$ with strong evidence of autosomal recessive inheritance. ${ }^{13}$ The disorder bears a striking resemblance to rheumatoid arthritis but differs radiologically owing to the absence of destructive bone changes and the presence of dysplastic bone changes in addition to the platyspondyly. The lack of response to anti-rheumatoid treatment is also a distinguishing feature.

We recently examined a 30 year old Arab female patient with double first cousin Lebanese parents. They had six normal daughters and two midtrimester miscarriages; there was no history of a similar condition in the family.

She appeared normal for the first $2 \frac{1}{2}$ years of life after which she developed difficulty in walking, swelling of the knees and small joints of the hands, followed by gradual stiffness in the knees. At the age of 5 years, a right genu valgum deformity was corrected surgically. Arthropathy of almost all limb joints was progressive and involved the elbows, wrists, hips, knees, and metaphalangeal and interphalangeal joints. By the age of 10 years, the small 